\title{
KONDISI TUTUPAN TERUMBU KARANG DI PULAU PANJANG TAMAN NASIONAL KEPULAUAN SERIBU, DKI JAKARTA
}

\author{
Yusuf Arief Nurrahman ${ }^{1}$, dan Ibnu Faizal ${ }^{2}$ \\ ${ }^{1}$ Jurusan Ilmu Kelautan, Fakultas Matematika dan Ilmu Pengetahuan Alam, Universitas Tanjungpura \\ Jln. Prof. Dr. H. Hadari Nawawi 78124, Pontianak, Kalimantan Barat, Indonesia \\ ${ }^{2}$ Departemen Kelautan, Fakultas Perikanan dan Ilmu Kelautan, Universitas Padjadjaran \\ Jln. Ir. Sukarno Km. 21 Bandung 40600, Jawa Barat, Indonesia \\ E-mail: yusuf.nurrahman@untan.ac.id
}

\begin{abstract}
ABSTRAK
Penelitian ini bertujuan untuk mengetahui kondisi komunitas terumbu karang di Pulau Panjang, Kepulauan Seribu. Pengambilan data primer dilaksanakan pada Bulan November 2016 dan data sekunder didapat dari penelitian lain di lokasi yang sama. Metode yang digunakan dalam penelitian ini adalah Transek Foto Bawah Air atau Underwater Photo Transect (UPT). Data lapangan berupa foto kemudian dianalisis dengan menggunakan perangkat Coral Point Count with excel extension (CPCe) untuk mengetahui kondisi terumbu karang di lokasi penelitian. Berdasarkan hasil pengamatan, kondisi komunitas terumbu karang di lokasi penelitian termasuk dalam kondisi cukup baik namun kategori kerusakannya adalah rusak sedang.
\end{abstract}

Kata kunci: Coral Point Count with excel extension; Keanekaragaman; Taman Nasional; Tutupan Karang; Underwater Photo Transect.

\section{CONDITION OF CORAL REEFS COVER IN PANJANG ISLAND, SERIBU ISLANDS NATIONAL PARK, JAKARTA}

\begin{abstract}
This study aims to know the coral reef community on Pulau Panjang, Thousand Islands. Primary data collection was carried out in November 2016 and secondary data was obtained from other studies in the same location. The method used in this study is the Underwater Photo Transect or Underwater Photo Transect (UPT). Field data consisted of photographs and then analyzed using the Coral Point Calculate tool with an excel extension (CPCe) to determine the condition of coral reefs at the study site. Based on the results of the study, the condition of the coral reef community at the study site was in a quite good condition but the category of damage was moderately damaged.
\end{abstract}

Keywords: Coral Point Count with excel extension; Diversity; National Park; Coral Covers; Underwater Photo Transect.

\section{PENDAHULUAN}

Terumbu karang sebagai salah satu ekosistem terpenting di lautan (Susanto et al., 2012), memiliki banyak ancaman terhadap kondisi terumbu karang antara lain akibat aktivitas manusia di dekatnya (Askar et al., 2018). Terumbu karang merupakan daerah dengan potensi wisata bahari yang sangat tinggi serta merupakan daerah penangkapan ikan yang utama dan memiliki kontribusi terhadap pendapatan lokal (Wilkinson, 2000). Ekosistem terumbu karang juga memiliki produktivitas primer yang tinggi sehingga ekosistem ini dapat dijadikan sebagai lokasi pemijahan, pengasuhan, serta mencari makan bagi banyak biota laut (Wu \& Zhang, 2012). Namun, terumbu karang merupakan ekosistem yang rentan terganggu, aktivitas manusia sebagai contohnya. Eksplotasi berlebihan oleh manusia seperti pembangunan wilayah pesisir yang tidak terintegrasi, sedimentasi, dan pencemaran perairan mengancam $58 \%$ ekosistem terumbu karang (Hughes et al., 2003). Kenaikan nutrient di dalam air akibat aktivitas manusia juga dapat membuat alga melimpah yang dimana alga merupakan kompetitor karang dalam pertumbuhan (Jompa \& McCook, 2003).

Taman Nasional Kepulauan Seribu terletak di lepas pantai utara Jakarta yang terdiri dari 110 pulau dengan luas $108.000 \mathrm{Ha}$, dengan posisi memanjang dari utara ke selatan yang ditandai oleh pulau-pulau kecil berpasir putih dan terumbu karang (Tomascik et al., 1997). Pulau Panjang berada di bagian utara kepulauan yang di pulau tersebut memiliki sebuah landas pacu pesawat terbang untuk kepentingan transportasi pariwisata di sekitar Kepulauan Seribu (BPS, 2018). Pulau Panjang juga berdekatan dengan beberapa pulau lain seperti Pulau Kelapa Dua, Pulau Kelapa, dan Pulau Harapan yang memiliki banyak aktivitas wisata maupun aktivitas warganya. Komunitas Terumbu Karang terdapat di sekeliling Pulau Panjang, sama seperti pulau lainnya di Kepulauan Seribu. Pulau Harapan yang terletak di sebelah tenggara Pulau Panjang memiliki tutupan karang mencapai 53.2\% (Nurrahman \& Nurdjaman, 2018). Aktivitas yang cukup masif di sekitar Pulau Panjang menjadi suatu tekanan yang dapat mempengaruhi keberadaan ekosistem terumbu karang di Pulau Panjang sehingga diperlukan suatu penelitian yang dapat mengetahui kondisi ekosistem terumbu karang di Pulau Panjang, Kepulauan Seribu.

\section{METODE}

Penelitian ini dilakukan dengan menggunakan metode kuantitatif. Pengambilan data dilakukan pada Bulan November 2016 di sekeliling Pulau Panjang. 
Metode pengambilan data yang dilakukan dalam penelitian ini meliputi beberapa tahapan, yaitu: (1) Pengamatan daerah yang akan diambil datanya dilakukan dengan menggunakan metode Manta tow untuk melihat kondisi umum terumbu karangnya dan mementukan titik transek. Daerah yang akan diambil datanya dipilih dengan pengamatan visual agar mewakili 5 kategori tutupan karang yang mengacu pada kategori penutupan karang yaitu 1-5\%, 6-30\%, 31-60\%, 61-75\% dan 75-100\% (Dahl, 1981); (2) Setelah didapat lokasi yang cocok, dilakukan penyelaman Self-Contained Underwater Breathing Apparatus (SCUBA) di setiap stasiun transek; (3) Kondisi tutupan terumbu karang dihitung berdasarkan data yang diambil dengan menggunakan metode Transek Foto Bawah Air atau Underwater Photograph Transect (UPT). Pengelompokan komunitas karang dilakukan menggunakan kategori bentuk kehidupan (life form) dengan melihat morfologi tutupan karang hidup/mati, substrat (pasir, lumpur), alga, dan biota lain.

Metode transek foto bawah air atau Underwater Photo Transect (UPT) sudah banyak diterapkan untuk pengambilan data karang karena lebih akurat dibandingkan dengan metode yang lain (Kohler \& Gill, 2006). Hal ini dikarenakan luasan area yang terwakili lebih besar, sehingga mampu merekam jenis-jenis karang, substrat ataupun biota benthos yang lain. Selain itu, adanya hasil foto juga dapat dijadikan bukti apabila nantinya akan diteliti ulang. Kelebihan lainnya adalah efisiensi waktu pengambilan data di lapangan sehingga penyelam tidak perlu melakukan kegiatan penyelaman terlalu lama (Giyanto, 2013). Pengambilan data dengan metode lain seperti LIT dapat menggunakan video namun diperlukan kemampuan daya apung (bouyancy skill) penyelam yang sangat baik dan tingkatan kecepatan tangkapan gambar atau fps (frame per second) kamera yang tinggi. Namun, kekurangan dari metode ini adalah saat proses pengolahan data, di mana dibutuhkan waktu yang cukup lama dalam melakukan analisis sampel fotonya (Adji et al., 2016).

Metode ini dimulai dengan melakukan pengamatan secara visual terhadap kondisi perairan dan terumbu karang secara umum seperti kondisi pantai, vegetasi yang ada, aktivitas penduduk, tipe terumbu (patch atau fringing reef), panjang reef flat secara tegak lurus garis pantai dan kondisi perairan (ombak dan arus) dan kemiringan lereng terumbu. Kemudian dilakukan pemasangan transek 50 meter di kedalaman 5-7 meter dan mengikuti bentuk dasar kemudian dicatat arah rintisan transeknya. Setelah transek terbentang, dilakukan pemasangan frame secara berganti sisi di setiap 1 meter transeknya sehingga didapat 50 frame foto yang setiap frame fotonya memiliki luas bidang foto minimal $1200 \mathrm{~cm}^{2}$ (Giyanto, 2013). Pada penelitian ini, frame yang digunakan pada setiap transek berukuran $50 \times 50 \mathrm{~cm}$, sehingga setiap bidang fotonya memiliki luas 2500 $\mathrm{cm}^{2}$. Pemotretan dilakukan secara vertikal diatas setiap kuadran dengan frame penuh. Visualisasi jalur transek serta posisi kuadran foto disajikan pada Gambar 1 .

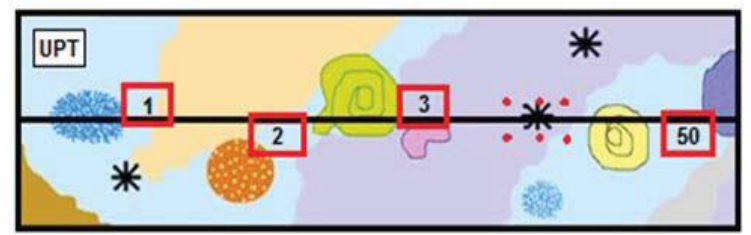

Gambar 1 Pola transek dengan metode UPT. (Sumber : Giyanto, 2013)

\section{Lokasi Penelitian}

Penelitian ini dilaksanakan di perairan Pulau Panjang yang secara administratif termasuk dalam Kabupaten Administrasi Kepulauan Seribu, Provinsi DKI Jakarta. Pengambilan data dilakukan di 5 (lima) stasiun dengan metode purposive sampling (Sugiyono, 2008) sesuai mata angin yaitu utara, timur, tenggara, barat, dan selatan. Koordinat tiap stasiun disajikan pada Tabel 1 dan Gambar 2.

Tabel 1 Posisi geografis stasiun.

\begin{tabular}{cccc}
\hline \multirow{2}{*}{ Stasiun } & \multicolumn{2}{c}{ Koordinat } & \multirow{2}{*}{ Posisi } \\
\cline { 2 - 3 } & Lintang & Bujur & \\
\hline P1 & $-5.642128^{\circ}$ & $106.562345^{\circ}$ & Utara \\
P2 & $-5.642463^{\circ}$ & $106.569300^{\circ}$ & Timur \\
P3 & $-5.643868^{\circ}$ & $106.567675^{\circ}$ & Tenggara \\
P4 & $-5.645532^{\circ}$ & $106.562453^{\circ}$ & Barat \\
P5 & $-5.646207^{\circ}$ & $106.552817^{\circ}$ & Selatan \\
\hline
\end{tabular}

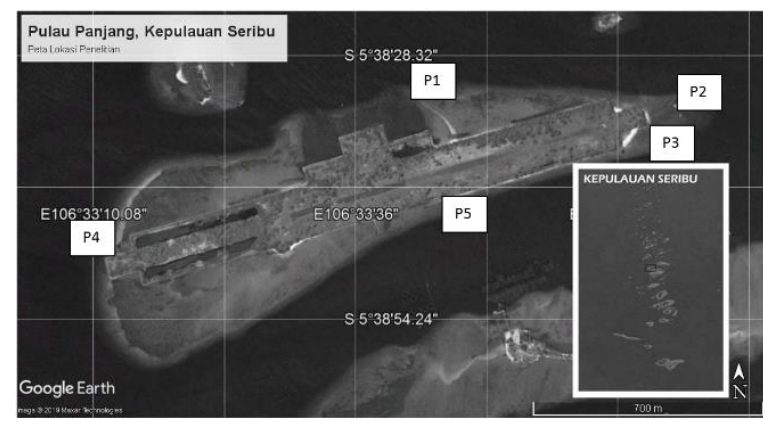

Gambar 2 Peta lokasi penelitian.

\section{Analisis Data}

Data lapangan berupa foto tiap frame diidentifikasi dengan menggunakan perangkat CPCe (Coral Point Count with excel extension) untuk mengklasifikasikan lifeform karang, tutupan karang, dan lainnya (Kohler \& Gill, 2006). Analisis foto pada perangkat CPCe dilakukan dengan beberapa tahapan yaitu penentuan frame foto, penentuan batasan frame, overlay titik acak, identifikasi substrat pada masing-masing titik acak, kemudian penyimpanan data yang selanjutnya dapat diolah dalam spreadsheet excel (Kohler \& Gill, 2006). Jumlah titik acak yang digunakan dalam satu frame foto yaitu sebanyak 50 titik acak. Penentuan jumlah titik acak ini ditentukan berdasarkan luasan frame foto. 
Selanjutnya persentase tutupan kategori pada setiap frame foto dihitung dengan menggunakan persamaan:

$$
\begin{aligned}
& \text { Persentase tutupan kategori }= \\
& \frac{\text { Jumlah titik kategori tersebut }}{\text { Jumlah titik acak }} \times 100
\end{aligned}
$$

Persentase tutupan dari setiap transek dapat menentukan kategori kondisi terumbu karang. Acuan kondisi terumbu karang berdasarkan persentase tutupan karang hidup dapat dilihat pada pada Tabel 2.

\section{HASIL DAN PEMBAHASAN}

Secara umum, terumbu karang di Pulau Panjang berada pada kondisi rusak sedang hingga rusak berat. Berdasarkan pengamatan didapatkan bahwa kondisi perairan sebelah utara Pulau Panjang merupakan daerah yang pernah dilakukan pengerukan untuk akses kapal ke dermaga. Pada saat diamati, banyak ditemukan jenis karang bercabang yang tumbuh di Perairan Pulau Panjang, sesuai dengan karakteristik terumbu karang Kepulauan Seribu pada umumnya yang didominasi karang bercabang (Faizal et al., 2019). Deskripsi karakteristik substrat dasar dari setiap titik stasiun pengamatan disajikan dalam Tabel 3.

Hasil pengamatan didapatkan kondisi terumbu karang yang beragam. Kondisi terumbu karang diklasifikasikan sesuai dengan Kepmen LH No. 4 Tahun 2001 tentang Kriteria Baku Mutu Kerusakan Terumbu Karang (Tabel 4).

Tabel 2 Kriteria penilaian kondisi terumbu karang.

\begin{tabular}{ccc}
\hline $\begin{array}{c}\text { Tutupan Karang } \\
\text { Hidup (\%) }\end{array}$ & $\begin{array}{c}\text { Kriteria Penilaian } \\
\text { (English } \text { et al., 1994) }\end{array}$ & $\begin{array}{c}\text { Status } \\
\text { (Kepmen LH No. 4 Thn 2001) }\end{array}$ \\
\hline $75-100$ & Sangat Baik & Baik sekali \\
$50-74.9$ & Baik & Baik \\
$25-49.9$ & Cukup Baik & Rusak sedang \\
$0-25$ & Kurang Baik & Rusak berat/Buruk \\
\hline
\end{tabular}

Tabel 3 Hasil pengamatan visual di lokasi.

Stasiun Deskripsi Lokasi

P1 Lokasi ini berada di sebelah utara Pulau Panjang, ditemukan terumbu karang dengan kondisi yang baik dengan kemiringan yang sangat curam. Ditemukan suksesi terumbu karang. Ditemukan banyak pecahan karang mati yang telah tumbuh kembali.

P2 Lokasi berada di timur Pulau Panjang. Terlihat daerah kosong di lokasi ini cukup miring. Terdapat banyak rubble.

P3 Lokasi berada di tenggara Pulau Panjang. Ditemukan banyak karang yang sudah mati dan beberapa batuan karang yang cukup besar. Terdapat hamparan pasir yang cukup luas dengan kemiringan landai.

P4 Lokasi ini berada di sebelah barat Pulau Panjang, ditemukan terumbu karang dengan kondisi yang cukup baik dengan kemiringan yang agak curam.

P5 Lokasi ini berada di sebelah selatan Pulau Panjang. Pada lokasi ini, ditemukan kondisi terumbu karang yang jarang (rusak) dan dengan kondisi yang cukup landai, namun ditemukan banyak Diadema (bulu babi) yang menjadi indikator pencemaran limbah organik.

Tabel 4 Kondisi terumbu karang tiap stasiun.

\begin{tabular}{cccc}
\hline Stasiun & $\begin{array}{c}\text { Tutupan Karang } \\
\text { Hidup (\%) }\end{array}$ & Kondisi & $\begin{array}{c}\text { Status Kerusakan } \\
\text { (Kepmen LH No. 4 Thn 2001) }\end{array}$ \\
\hline P1 & 43.2 & Cukup baik & Rusak sedang \\
P2 & 6.26 & Kurang baik & Rusak berat \\
P3 & 5 & Kurang baik & Rusak berat \\
P4 & 42.4 & Cukup baik & Rusak sedang \\
P5 & 19.04 & Kurang baik & Rusak berat \\
\hline
\end{tabular}




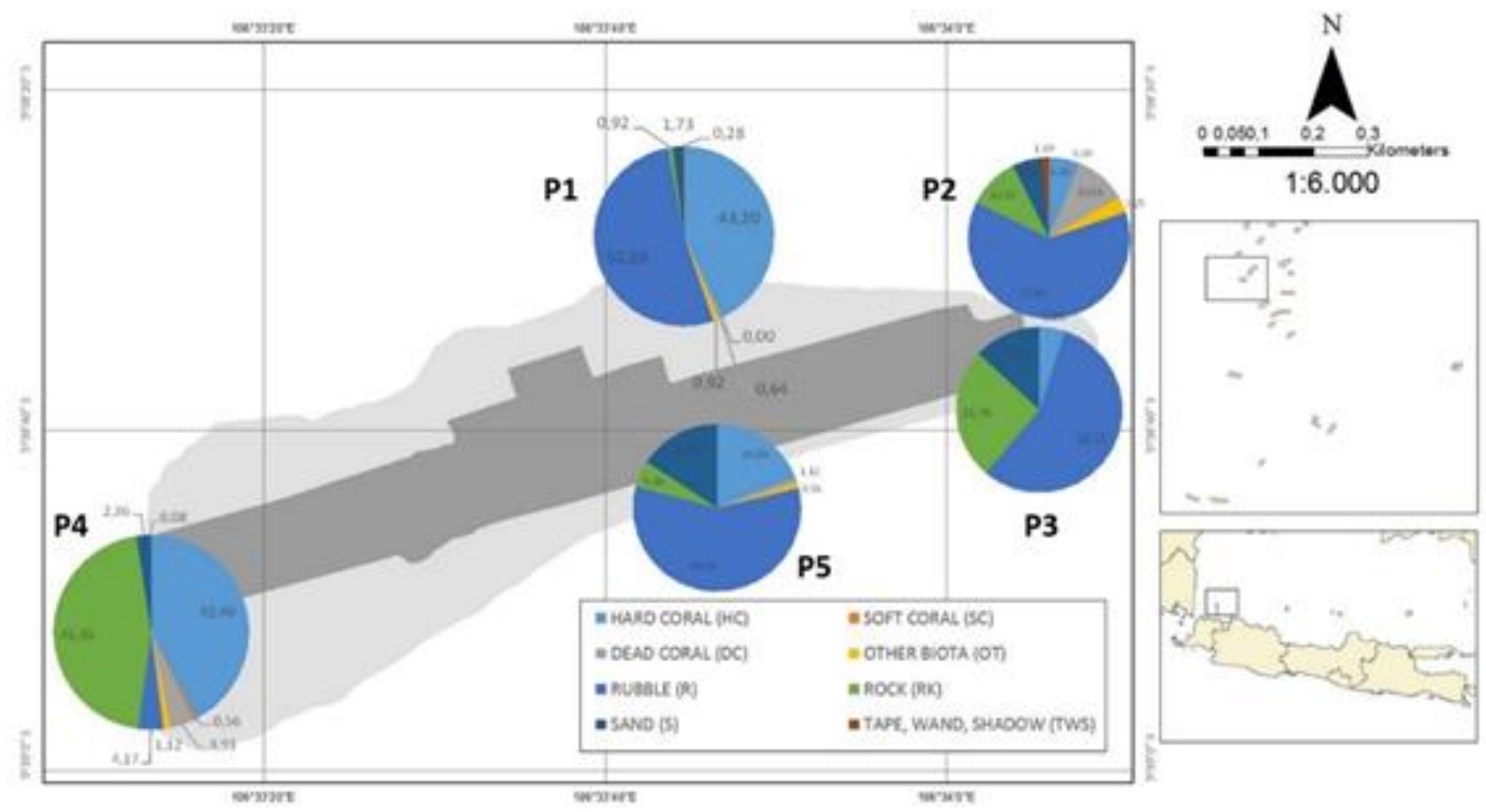

Gambar 3 Sebaran Kondisi tutupan karang hidup Pulau Panjang.

Hasil penelitian menunjukkan bahwa kondisi terbaik berlokasi di stasiun P1 yang berlokasi di sebelah utara Pulau Panjang dengan tutupan karang hidup sebesar 43.2\%. Stasiun P4 yang terletak di sebelah barat Pulau Panjang juga menunjukkan tutupan karang hidup yang cukup baik yaitu sebesar 42.3\%. Kondisi terburuk ditemukan pada stasiun P3 di bagian tenggara Pulau Panjang dengan tutupan karang hidup hanya 5\% (Gambar 3).

Rubble banyak didapatkan di lokasi setiap lokasi seperti yang disajikan pada Tabel 5. Persentase rubble melebihi $50 \%$ dari jumlah persentase tutupan karang di 4 lokasi stasiun pengamatan. Hanya P4 (Barat) yang memiliki persentase di bawah 5\% (4.17\%). Rubble sebagaian besar berasal dari karang jenis bercabang (branching).

Tabel 5 Persentase rubble.

\begin{tabular}{cc}
\hline Stasiun & Pecahan Karang $(\%)$ \\
\hline P1 & 52.59 \\
P2 & 63.49 \\
P3 & 56.12 \\
P4 & 4.17 \\
P5 & 58.04 \\
\hline
\end{tabular}

Karang dengan jenis cabang seperti Acropora walaupun memiliki tingkat pertumbuhan yang lebih cepat mencapai $0.148 \mathrm{~mm}$ namun memiliki kerentanan yang tinggi (Muhlis, 2019). Berbeda dengan karang jenis masif di mana karang jenis masif dan sub-masif lebih toleran terhadap sedimentasi yang tinggi dan eutrofikasi, sehingga jenis-jenis ini disebut sebagai "stress-tolerators"
(Edinger \& Risk, 2000). Selain itu, karang jenis cabang yang berukuran kecil juga sangat rentan terhadap gangguan dibandingkan dengan jenis tabular/masif (Mutmainah \& Clara, 2017).

Kerusakan terumbu karang di wilayah ini disebabkan oleh beberapa hal diantaranya yaitu alamiah dan kegiatan manusia. Kerusakan yang diakibatkan oleh alam yaitu seperti meningkatnya suhu permukaan laut akibat adanya perubahan iklim (Hughes et al., 2017; McWilliams et al., 2005), kondisi oseanografi perairan juga mempengaruhi, di mana arus berperan dalam perpindahan partikelpartikel yang ada di kolom air (Maharani et al., 2018), salah satunya sedimen. Pembangunan dermaga yang di mana dalam prosesnya dilakukan pengerukan berpotensi menyebabkan terjadinya sedimentasi yang dapat menganggu kehidupan terumbu karang (Faizal \& Yuanita, 2017; Askar et al., 2018; Loiola et al., 2019). Penyebab kerusakan terumbu karang berikutnya adalah aktivitas manusia (Mutmainah \& Clara, 2017) baik yang mempengaruhi secara langsung maupun tidak langsung seperti penangkapan ikan dengan menggunakan bahan peledak, bahan beracun, pencongkelan dan penggalian karang (Santoso, 2010).

Rehabilitasi terumbu karang dibutuhkan melihat pentingnya ekosistem ini terhadap banyak aspek, keberlangsungan hidup biota yang berasosiasi didalamnya yang paling utama (van Oppen et al., 2015). Pembangunan wilayah pesisir dan pulaupulau kecil harus memperhatikan faktor konektivitas larva karang (Fitriadi et al., 2017) sehingga tidak menganggu proses keberlangsungan terumbu karang secara alami. 


\section{SIMPULAN}

Simpulan yang didapatkan dari penelitian ini adalah kondisi terumbu karang di Pulau Panjang, Kepulauan Seribu, DKI Jakarta memiliki kondisi yang beragam dari sedang hingga buruk. Kondisi terbaik terdapat pada stasiun P1 di sebelah utara dengan tutupan karang hidup sebesar $43.2 \%$, sedangkan yang terburuk yaitu pada stasiun P3 di sebelah tenggara dengan tutupan karang hidup hanya $5 \%$. Kategori substrat dasar dengan tutupan pecahan karang banyak ditemukan di setiap stasiun menunjukkan bahwa terumbu karang dalam kondisi rusak.

\section{UCAPAN TERIMA KASIH}

Penulis mengucapkan terima kasih kepada Kementerian Koordinator Kemaritiman, Deputi Bidang Koordinasi Sumber Daya Manusia, Ilmu Pengetahuan dan Teknologi, dan Budaya Maritim melalui Program Indonesia Coral Reef Garden (ICRG), Kelompok Keahlian Oseanografi Institut Teknologi Bandung serta tim penyelam yang membantu proses pengambilan data.

\section{DAFTAR PUSTAKA}

Adji AS, Indrabudi T \& Alik R. (2016). Penerapan Metode Foto Transek Bawah Air untuk Mengetahui Tutupan Terumbu Karang di Pulau Lombo, Maluku. Jurnal Ilmu dan Teknologi Kelautan Tropis, 8, (2), 633-643.

Askar AT, Agung MUK, Andriani Y \& Yuliadi LP. (2018). Kelimpahan Bakteri Coliform pada Air Laut, Sedimen dan Foraminifera Jenis Calcarina di Ekosistem Terumbu Karang Pulau Pramuka, Kepulauan Seribu, DKI Jakarta. Jurnal Akuatika Indonesia, 3, (1), 3641.

[BPS] Badan Pusat Statistik. (2018). Kepulauan Seribu dalam Angka Tahun 2018. BPS Kepulauan Seribu. DKI Jakarta: BPS Kepulauan Seribu.

Dahl AL. (1981). Coral Reef Monitoring Handbook. Sydney: South Pacific Commission, Noumea, New Caledonia. 21p.

Edinger EN \& Risk MJ. (2000). Reef Classification by Coral Morphology Predicts Coral Reef Conservation Value. Biological Conservation, 92, (1), 1-13.

English S, Wilkinson C \& Bakert V. (1994). Survey Manual for Tropical Marine Resources. Townville: Australian Institute of Marine Science. 368p.

Faizal I \& Yuanita N. (2017). Study of Coral Reef Ecosystem Vulnerability using Sediment Transport Modeling in Bungus Bay, West Sumatera. International Journal of Science and Research, 6, (6), 176-180.
Faizal I, Iriana D, Riyantini I \& Purba NP. (2019). The Status of Coral Reefs in The Seribu Islands National Park, Indonesia in Various Zones. Global Scientific Journal, 7, (10), 165175.

Fitriadi CA, Dhahiyat Y, Purba NP, Harahap SA \& Prihadi DJ. (2017). Coral Larvae Spreading Based on Oceanographic Condition in Biawak Islands, West Java, Indonesia. Biodiversitas, 18, (2), 681-688.

Giyanto. (2013). Metode Transek Foto Bawah Air Untuk Penilaian Kondisi Terumbu Karang. Oseana, 38, (1), 47-61.

Hughes TP, Baird AH, Bellwood DR, Card M, Connolly SR, Folke C, Grosberg R, HoeghGuldberg O, Jackson JBC, Kleypas J, Lough JM, Marshall P, Nystro m M, Palumbi SR, Pandolfi JM, Rosen B \& Roughgarden J. (2003). Climate Change, Human Impacts, And The Resilience of Coral Reefs. Science, 301, (5635), 929-933.

Hughes T, Kerry J, lvarez-Noriega M, AlvarezRomero J, Anderson K, Baird A. (2017). Global Warming and Recurrent Mass Bleaching of Corals. Nature, 543, (7645), 373-377.

Jompa J \& McCook LJ. (2003). Coral-alga Competition: Macroalga with Different Properties have Different Effect on Corals. Marine Ecology Progress Series, 258, 87-95.

Kohler KE \& Gill SM. (2006). Coral Point Count with Excel Extensions (CPCe): A Visual Basic Program for The Determination of Coral and Substrate Coverage Using Random Point Count Method-logy. Computers and Geosciences, 32, (9), 1259-1269.

Loiola M, Cruz ICS, Lisboa DS, Mariano-Neto E, Leão ZMAN, Oliveira MDM \& Kikuchi RKP. (2019). Structure of Marginal Coral Reef Assemblages Under Different Turbidity Regime. Marine Environmental Research, 147, 138-148.

Maharani A, Purba, NP, Faizal I. (2018). Occurrence of Beach Debris in Tunda Island, Banten, Indonesia. SciFiMas E3S Web of Conferences (pp 1-12), 47, 04006, 1-12.

McWilliams JP, Côté IM, Gill JA, Sutherland WJ, Watkinson AR. (2005). Accelerating Impacts of Temperature-induced Coral Bleaching in The Caribbean. Ecology, 86, (8), 2055-2060.

Muhlis. (2019). Pertumbuhan Kerangka Karang Acropora di Perairan Sengigi Lombok. Jurnal Biologi Tropis, 19, (1), 14 -18.

Mutmainah H \& Clara RS. (2017). Analisa Sebaran Tutupan dan Indeks Mortalitas Terumbu Karang di Perairan Sekitar Selat Pagai Mentawai. Jurnal Akuatika Indonesia, 2, (1), 43-57.

Nurrahman YA \& Nurdjaman S. (2018). Primary Productivity of Coastal Ecosystems in The Seribu Islands (Case Study on Kelapa Dua 
Island, Pramuka Island and Pari Island). IOP Conf Series: Earth and Envi-ronmental Science (pp 1-9), 162, 012025.

Santoso AD. (2010). Kondisi Terumbu Karang di Pulau Congkak Kepulauan Seribu. Jurnal Hidrosfir Indonesia, 5, (2), 73-78.

Sugiyono. (2008). Metode Penelitian Kuantitatif Kualitatif dan $R \& D$. Bandung: Alfabeta

Susanto AS, Suraji \& Tokeshi M. (2012). Management of Coral Reef Ecosystems in Indonesia: Past, Present, and The Future. Coastal Ecosystem, 2, 21-41.

Tomascik T, Mah AJ, Nontji A \& Moosa MK. (1997). The Ecology of Indonesian Seas. First Edition. Singapore: Periplus Editions (HK) Ltd.

van Oppen MJH, Oliver JK, Putnam HM \& Gates RD. (2015). Building Coral Reef Resilience
Through Assisted Evolution. Proceedings of the National Academy of Sciences (pp. 23207 - 2313). USA: National Academy of Sciences.

Wilkinson CE. (2000). Status of Coral Reefs Of The World. Townsville, Queensland: Australian Institute of Marine Science (AIMS) and Global Coral Reef Monitoring Network (GCRMN).

Wu SH \& Zhang WJ. (2012). Current Status, Crisis and Conservation of Coral Reef Ecosystem in China. The International Academy of Ecology And Environmental Sciences Proceedings (pp. 1-11). Hongkong: International Academy of Ecology and Environmental Sciences (IAEES). 